\title{
Echocardiographic findings in children with Tetralogy of Fallot
}

\author{
Urmila Shakya, Poonam Sharma, Manish Shrestha \\ Department of Pediadtric Cardiology, Shahid Gangalal National Heart Centre Bansbari Kathmandu, Nepal \\ Correspoding Author: Poonam Sharma, Department of Pediadtric Cardiology, Shahid Gangalal National Heart Centre Bansbari \\ Kathmandu, Nepal, Email: medpoonam@gmail.com
}

\section{Abstract}

\begin{abstract}
Background and Aims: Tetralogy of Fallot (TOF) is the most common cyanotic congenital heart disease in children. The aim of this study was to identify various cardiac defects associated with TOF by transthoracic echocardiography.

Methods: All children presenting to Shahid Gangalal National Heart Centre, with the diagnosis of TOF from 2014 to 2015 were included in the study. Echocardiograpic reports of all eighty eight children were reviewed.

Results: The mean age of presentation was $3.5 \pm 3.9$ years. Fifty six $(64 \%)$ children were male and thirty two $(36 \%)$ were female. Pulmonary artery anomaly was found in nine $(10.2 \%)$ children which included hypoplastic pulmonary arteries, absent left pulmonary artery, post stenotic and aneurysmal dilatation of pulmonary artery. Pulmonary valve anomalies were seen in $13(14.8 \%)$ children which include pulmonary atresia, pin-hole opening of valve and bicuspid and absent pulmonary valve. Double outlet right ventricle, patent ductus arteriosus/major aortico-pulmonary collaterals, atrial septal defect and persistent left superior venacava were present in 12 (13.6\%), 21 (23.9\%), $22(22.7 \%)$ and nine (10.2\%) respectively. Right sided aortic arch was seen in 20 (22.7\%).

Conclusion: TOF is associated with various anatomical variations which need to be identified to avoid surgical complications. These can be diagnosed by echocardiography which has greatly reduced the need for invasive cardiac catheterization for these patients.
\end{abstract}

Key words: children, echocardiography, Tetralogy of Fallot

\section{Introduction:}

Tetralogy of Fallot (TOF) is the most common cyanotic congenital heart disease in infants and children accounting for $3.5 \%$ of all congenital heart disease. ${ }^{1}$ The clinical features of TOF depend on the severity of right ventricular outflow tract (RVOT) obstruction. Some children with minimal RVOT obstruction have history similar to ventricular septal defect (VSD) without cyanosis whereas those with pulmonary atresia have marked cyanosis with greatly reduced pulmonary blood flow which may be entirely dependent on patent ductus arteriosus (PDA). The symptom of TOF is also dependent on the site of obstruction of RVOT. Children with infundibular stenosis have a more dramatic dynamic spasm presenting as classic hypercyanotic spell. ${ }^{2}$

Many associations were described with this common cyanotic heart disease in the literature. However till date no study has been conducted in such children in Nepal. Hence this study has been conducted to note the common features and association among Nepalese children suffering from TOF.

\section{Methods:}

It was a single centre retrospective observational study conducted in Shahid Gangalal National Heart
Centre for one year from 14th April 2014 to 13th April 2015. The echocardiographic findings of all children with the diagnosis of TOF or TOF physiology were reviewed. The study was approved by the ethical committee of Instituitional Review Board of National Heart Centre. Informed consent was taken from the parents/guardians.

The data was evaluated by SPSS Statistics 20 . Variables such as age and gender were presented as simple descriptive statistics. Mean and standard deviation of numeric data and frequency/percentage of qualitative data was calculated. Outcome variables such as associated lesion and anatomic variations were calculated in percentage.

\section{Results:}

A total of 88 patients were diagnosed with TOF within the study period of one year. Children from birth till 15 years were evaluated.Among the study population, 56 (63.6\%) children were male and $32(36.4 \%)$ were female. The mean age of presentation was $3.5 \pm 3.9$ years. Majority of children were less than one year of age including 39 (44.4\%) children followed by age between 1 to 5 year of age which were $29(32.3 \%)$ children. Only $9(9.4 \%)$ children were older than 10 years. 


\begin{tabular}{|lcc|}
\hline \multicolumn{2}{l}{ Table 1: Age distribution } & \\
\hline Frequency & Number of children & Percentage \\
\hline$<1$ month & 7 & 8.0 \\
\hline$<1$ year & 32 & 36.4 \\
\hline 1-5 years & 29 & 33.0 \\
\hline $5-10$ years & 11 & 12.5 \\
\hline$>10$ years & 9 & 10.2 \\
\hline
\end{tabular}

All the children had levocardia except for two cases, one with situs inversus with dextrocardia and the other with mesocardia. Pulmonary artery anomaly was present in nine $(10.2 \%)$ children. Hypoplastic and small pulmonary arteries was seen in four patients and one child had absence of left pulmonary artery. Post stenotic dilatation was seen in three children and another child with stenotic pulmonary valve had aneurysmal dilatation of right and left pulmonary artery.

Abnormalities of pulmonary valve were seen in $13(14.8 \%)$ children. Among them pulmonary atresia was present in eight $(9.1 \%)$ and small pinhole opening of pulmonary valve was present in four (4.5\%) children. Pulmonary valve was bicuspid in one and absent in another child. Double outlet right ventricle (DORV) defined by absence of mitral aortic fibrous continuity or overriding of aorta $>50 \%$, was present in $12(13.6 \%)$ children. PDA or MAPCAs were present in 21 (23.9\%), ASD in 20 (22.7\%) and persistence of left superior venacava was present in 9 $(10.2 \%)$ children. Similarly right sided aortic arch (RAA) was seen in $20(22.7 \%)$ children.

Table 2: Associated Abnormalities in TOF patients

\begin{tabular}{|lcc|}
\hline \multicolumn{1}{|c}{ Abnormality } & $\begin{array}{c}\text { Number of } \\
\text { children }\end{array}$ & $\begin{array}{c}\text { Percentage } \\
\text { of children }\end{array}$ \\
\hline Pulmonary artery anomalies & 9 & $10.2 \%$ \\
\hline Pulmonary valve a bnormalities & 13 & $14.8 \%$ \\
\hline PDA/MAPCAs & 21 & $23.9 \%$ \\
\hline ASD & 20 & $22.7 \%$ \\
\hline PLSVC & 9 & $10.2 \%$ \\
\hline DORV & 12 & $13.6 \%$ \\
\hline Right sided aortic arch & 20 & $22.7 \%$ \\
\hline
\end{tabular}

Table 3: Abnormalities of Pulmonary valve and Pulmonary artery

Pulmonary Artery Anomaly Pulmonary Valve Anomaly

\begin{tabular}{lcll|} 
Abnormality & $\begin{array}{c}\text { No } \\
\text { (Percent) }\end{array}$ & $\begin{array}{l}\text { P u } 1 \mathrm{~m} \text { o n a r y } \\
\text { Atresia }\end{array}$ & $\begin{array}{c}\text { No } \\
\text { (Percent) }\end{array}$ \\
\hline $\begin{array}{l}\text { Hypoplastic } \\
\text { Pulmonary } \\
\text { Artery }\end{array}$ & $4(4.5 \%)$ & Pulmonary Atresia & $8(9 \%)$ \\
\hline $\begin{array}{l}\text { Absence of } \\
\text { LPA }\end{array}$ & $1(1.1 \%)$ & $\begin{array}{l}\text { Pin hole opening } \\
\text { of PA }\end{array}$ & $4(4.5 \%)$ \\
\hline $\begin{array}{l}\text { Post stenotic } \\
\text { dilatation of } \\
\text { PA }\end{array}$ & $3(3.4 \%)$ & $\begin{array}{l}\text { Bicuspid } \\
\text { pulmonary valve }\end{array}$ & $1(1.1 \%)$ \\
\hline $\begin{array}{l}\text { Aneurysmal } \\
\text { dilatation of } \\
\text { RPA and LPA }\end{array}$ & $1(1.1 \%)$ & $\begin{array}{l}\text { Absent pulmonary } \\
\text { valve }\end{array}$ & $1(1.1 \%)$ \\
& & & \\
\hline
\end{tabular}

The frequency of the site of pulmonary stenosis is shown in Table 4. The most common type of pulmonary stenosis was combination of infundibular and valvular stenosis occuring in $57(64.8 \%)$ of children with isolated valvular and combination of supravalvular and valvular stenosis being the least common.

Table 4: Site of Obstruction in Right Ventricular Outflow Tract

\begin{tabular}{lcc|}
\hline Site of obstruction & Number of children & Percentage \\
\hline Infundibular & 5 & 5.7 \\
\hline Valvular & 1 & 1.1 \\
\hline $\begin{array}{l}\text { Infundibular and } \\
\text { Valvular }\end{array}$ & 57 & 64.8 \\
\hline $\begin{array}{l}\text { Supravalvular and } \\
\text { Valvular }\end{array}$ & 1 & 1.1 \\
\hline $\begin{array}{l}\text { In fun dibul a r }, \\
\text { Valvular and } \\
\text { Supravalvular }\end{array}$ & 24 & \\
\hline
\end{tabular}

\section{Discussion:}

TOF is the most common cyanotic congenital heart disease in children beyond the neonatal period seen in $3.5 \%$ of all infants with congenital heart disease with an incidence of 0.28/1000 live births. ${ }^{3}$ Although first identified by Niels Stenson in 1671, the precise anatomical description was given by William Hunter in 1784 as a communication between two ventricles with obstruction to the pulmonary artery flow. ${ }^{4}$ The anatomical defect, its pathological features and the clinical implications were later described by Louis Arthur Fallot in 1888 as 'cyanose cardiaque' (cardiac cyanosis). ${ }^{5}$ It was however a Canadian Pediatric Cardiologist Maude 
Abbott in 1924 who coined the term Tetralogy of Fallot (tetrad of VSD, right ventricular outflow obstruction, over riding of aorta and right ventricular hypertrophy). ${ }^{2}$ Nowadays we consider TOF to be a family of diseases with similar intra cardiac anatomy but with variability of pulmonary artery anatomy, other associated anomalies and outcomes.

Although TOF is said to have an equal gender prevalence, 2,6 our study revealed it to be more common in males (65:35). Similar finding was noted by studies done in Iran and Pakistan., The mean age of children in our study group was $3.5 \pm 3.9$ years with most cases (44\%) being less than one year of age. This is comparable to a study done in Turkey where children presented at an age of $3.9 \pm 2.9$ years. However studies in Pakistan have reported delayed presentation. $^{8}$

Various authors have mentioned about different anomalies associated with TOF. Most of these associations have been identified by cardiac catheterization. We have however studied the association identified by transthoracic echocardiography without any invasive procedures and our findings are comparable to those identified by catheterization. Pulmonary artery anomaly was found in $10.2 \%$ of TOF children in our study, which was similar to Farsani et al. ${ }^{7}$ This is however slightly lower than that noticed by Sheikh et al where pulmonary artery anomaly was seen in $19 \%$ of children with TOF. ${ }^{10}$ This could be because Sheikh et al have included supra valvular stenosis as a pulmonary artery anomaly.

Pulmonary Atresia is one of the known anatomic variant of TOF which is present in $5-10 \%$ of all TOF cases. ${ }^{11}$ Our study also revealed pulmonary atresia to be the most common valve abnormality seen in $9 \%$ of children with TOF.

PDA/MAPCA was the most common abnormality in our study which was present in $24 \%$ of children followed by ASD present in $22 \%$. The percentage of PDA/MAPCA could be high in our study because we have also included TOF with Pulmonary Atresia where the pulmonary circulation is entirely dependent on PDA. Similar finding was noted in Pakistan where PDA and MAPCAs were present in 20\% of children. ${ }^{9}$ Although right sided aortic arch is of little clinical significance, it is one of the frequent anomalies seen in TOF and needs to be correctly notified to the surgeons prior to the surgery to avoid complications. In our study RAA was present in $22 \%$ of children. Similar finding was seen in Iran where it was seen in $21 \%$ of children. ${ }^{7}$ Saeed et al noted a much lower incidence of RAA in TOF patients. ${ }^{8}$

TOF is known to be associated with double outlet right ventricle. In our study, DORV was present in $13.6 \%$ of the children. This is comparable to a study done in Turkey, where DORV was present in $9.5 \%$ of TOF patients. $^{9}$

Although TOF is a common congenital anomaly, reports of its association with dextrocardia and situs inversus which was first reported by Scragg and Denny in $1952^{12}$ are few. We have found one such case TOF in a child with situs inversus.

The most common site of obstruction in our study was a combination of infundibular and valvular stenosis which was present in $65 \%$ of children. Infundibular stenosis was present in $97.8 \%$, valvular in $94.3 \%$ and supravalvular in $28.8 \%$ of children. Agrawal et al in India have noted subvalvular stenosis to be present in $96.1 \%$, valvular in $83.9 \%$ and supravalvular in $33.3 \%$ of children. ${ }^{13}$

Despite all these associated abnormalities, our study lacked to show coronary artery abnormalities found not infrequently in patient with TOF. Some of the coronary information may be crucial for the definitive repair. Certainly this is one of the limitations of our study. Further, the study has limitations of being single centre and retrospective design.

\section{Conclusion:}

TOF is the most common cyanotic congenital heart disease encountered in a cardiac clinic and has many associations. Although in the past cardiac catheterization was necessary in all the children with TOF to identify the exact anatomy and known variation, improvement in transthoracic echocardiography has significantly reduced the necessity of these invasive procedures in children.

\section{References}

1 Linde D, KoningsEEM, SlagerMA, et al.Birth Prevalence of Congenital Heart Disease: Worldwide A Systematic Review and MetaAnalysis. JACC 2011;58: 2242-7.

2 Bonchek LI, Starr A,Sunderland CO, et al. Natural History of Tetralogy of Fallot in Infancy Clinical Classification and Therapeutic Implications. Circulation 1973;48: 392-7.

3 Apitz C, Webb GD, Redington AN. Tetralogy of Fallot. The Lancet 2009;374: 1462-71.

4 Praagh RV. The First Stella Van Praagh Memorial Lecture: The History and Anatomy of Tetralogy of Fallot. Pediatric Cardiology Surgical Annual 2009;12:19-38.

5 Swamy P, Bharadwaj A, Varadarajan P, et al. Echo in adult congenital heart disease; Echocardiographic Evaluation of Tetralogy of Fallot.Echocardiography 2015;32:S148-S156.

6 Bailliard F, Anderson RH.Tetralogy of Fallot. Orphanet Journal of Rare Diseases 2009;4: 1-10.

7 Farsani HY, Moghadam MYA. Characteristics of TOF in Iranian Patients. Iran J Pediatr 2007;17: 5-10.

8 SaeedS,HyderSN,SadiqM.AnatomicalVariations of Pulmonary Artery and AssociatedCardiac Defects in Tetralogy of Fallot.Journal of the College of Physicians and Surgeons Pakistan 2009;19: 211-4. 
9 Kervancioglu M, Tokel K, Varan B, et al. Frequency, origins and courses of anomalous coronary arteries in 607 Turkish children with tetralogy of Fallot. Cardiology Journal 2011;18: 546-51.

10 Sheikh AM, KazmI U, Syed NH, et al. Variations of pulmonary arteries and other associated defects in Tetralogy of Fallot. SpringerPlus 2014;3:467-70.

11 Dobrocky T, Klink T, Weisstanner C, et al. Imaging findings in uncorrected tetralogy of Fallot and pulmonary atresia with major aortopulmonary collateral arteries and septic embolism.Acta Radiologica Short Reports 20014;3: 1-4.

12 DiLorenzo M, Weinstein S, Shenoy R. Tetralogy of Fallot with Dextrocardia and Situs Inversus in a 7-Year-Old Boy. Tex Heart Inst J 2013;40:481-3.

13 Agrawal S, Soni D, Dhawan S, et al. Sites of right ventricular outflow tract obstruction in tetralogy of Fallot--a retrospective study. Indian Heart J 1991;43:455-9.

Cite this article as: Urmila Shakya, Poonam Sharma, Manish Shrestha. Echocardiographic findings in children with Tetralogy of Fallot. Nepalese Heart Journal 2015;12(2):65-68. 